Rev. Estud. Ling., Belo Horizonte, v. 28, n. 3, p. 1347-1371, 2020

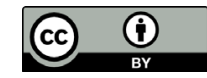

\title{
Análise cognitivo-discursiva de metáforas e mesclas (blends) multimodais presentes em um blog político brasileiro
}

\author{
Cognitive-discursive analysis of multimodal metaphors \\ and blends present in a Brazilian political blogs
}

\author{
Paulo Henrique A. Mendes \\ Universidade Federal de Ouro Preto (UFOP), Ouro Preto, Minas Gerais / Brasil \\ pauloufop01@gmail.com \\ https://orcid.org/0000-0003-0584-0669
}

Resumo: Este trabalho pretende analisar de um ponto de vista cognitivo e discursivo o uso de metáforas e blends multimodais sobre política presentes em um blog político brasileiro. Nesse sentido, interessa avaliar o modo pelo qual diferentes sistemas semióticos coexistem na construção de processos constitutivos desse gênero digital, a exemplo de recursos verbais e imagéticos. Isso possibilita um aprofundamento do conhecimento acerca das crenças, valores e ideologias políticas que caracterizam os discursos sobre democracia. Além disso, este estudo permite também avaliar como o desenvolvimento das tecnologias de informação e comunicação, a exemplo da blogosfera, engendram novas formas de discussão e de participação política, viabilizando, sobretudo, a produção de novas estratégias cognitivas e discursivas, através da exploração de diferentes recursos semióticos. Nesse sentido, as operações de metaforização e/ou de mesclagem, enquanto constitutivas do modo de pensar, agir e se comunicar dos seres humanos emergem como objetos privilegiados de uma abordagem cognitivo-discursiva dos blogs políticos, em função de sua recorrência e relevância nesse(s) gênero(s). Assim, os blogs políticos são concebidos como espaços semióticos que emergem da interação entre os sujeitos e as novas mídias digitais, produzindo sentido através da integração de diferentes recursos semióticos. Essa interação engendra processos metafóricos e/ou mesclagens representativas do modo pelo qual esses sujeitos, enquanto cidadãos, experienciam o espaço público e agem politicamente através do discurso, posicionando-se, debatendo e, por vezes, manipulando as opiniões.

Palavras-chave: metáforas e blends multimodais; cognição; discurso; blogs políticos. 


\begin{abstract}
This work intends to analyze from a cognitive and discursive point of view the use of multimodal metaphors and blends about politics in Brazilian political blogs. It is interested in evaluating the way in which different semiotic systems coexist in the construction of constitutive processes of this digital genre with special reference to verbal and imaginary resources. It is meant to enhance knowledge about the beliefs, values and political ideologies that characterize the discourses on democracy. Moreover, it allows us to evaluate how the development of information and communication technologies has crafted new forms of discussion and political participation by enabling new cognitive and discursive strategies. The use of metaphors and blends, while constitutive of the way human beings think, act and communicate, can be accounted for as recurrent framings in political blogs from a cognitive-discursive approach. Hence, that political blogs can be dealt with as semiotic mental spaces that emerge from the interaction between subjects and new digital media, producing meaning through the conceptual integration of different semiotic resources. This interaction engenders metaphorical and blending processes as representations of how these subjects, as citizens, experience the public space and act politically through discourse by taking stances, debating and sometimes manipulating opinions.
\end{abstract}

Keywords: multimodal metaphors and blends; cognition; discourse; political blogs.

Submetido em 20 de dezembro de 2019

Aceito em 17 de fevereiro de 2020

\title{
1. Introdução
}

Neste artigo, propomos avaliar os processos de metaforização e de mesclagem multimodais no gênero blog político. Assumimos como perspectiva central a relevância desses processos multimodais como constitutivos da linguagem e da produção de sentido em geral, buscando ilustrá-los através da análise de um exemplo de blog político brasileiro. Trata-se de uma análise qualitativa por amostragem sem a pretensão de ser exaustiva. Essa escolha relaciona-se ao fato de que é amplamente reconhecido que os estudos acerca dos processos metafóricos e de mesclagem multimodais têm sido desenvolvidos de forma consistente, consolidando-se como uma das principais vertentes de pesquisa da linguística e da semiótica cognitivas, sendo também considerados no âmbito dos estudos enunciativos e discursivos, mais recentemente. Ao mesmo tempo, assistimos a um desenvolvimento vertiginoso das 
tecnologias da informação e da comunicação, que tem transformado a internet e as plataformas de redes sociais em suportes privilegiados de produção, circulação e recepção dos discursos sociais de um modo geral e, mais especificamente, dos discursos políticos. Assim, desenvolvemos uma reflexão que busca articular um objeto teórico da relevância das metáforas e das mesclagens multimodais a uma análise de um objeto empírico com a complexidade e a importância que os blogs políticos têm assumido na contemporaneidade. Selecionamos um exemplo de postagem do blog Tijolaço, de Fernando Brito, para ilustrar nossa análise.

\section{Processamento neuronal, percepção e representação da multimodalidade}

Os estudos sobre a relação entre cognição e linguagem, a partir de uma abordagem experiencial, baseada em fundamentos fenomenológicos e enativos, coloca em questão uma dimensão ecológica da relação entre organismo e ambiente, na qual a noção de multimodalidade tende a assumir um lugar proeminente. Trata-se de assumir, em toda a sua complexidade, a multimodalidade como um princípio de funcionamento do organismo em sua integração com o ambiente e vice-versa. Como construímos os espaços interacionais e produzimos sentidos multimodalmente, ou seja, como uma ação (verbal ou não) é construída graças a uma ecologia de sistemas perceptivos e/ou de signos, estruturalmente distintos entre si, mas intrinsecamente relacionados? Há um grande desafio colocado para a construção de metodologias e ferramentas de análise para lidar com objetos dessa complexidade.

Nesse sentido, a própria noção de multimodalidade precisa ser melhor balizada, com vistas a tornar mais claro o seu teor conceitual e analítico. Uma primeira dimensão importante a ser considerada refere-se aos estudos relacionados ao processamento neurofisiológico da multimodalidade, como um fundamento básico do ponto de vista ontológico e epistemológico para uma discussão mais efetiva sobre os seus desdobramentos nos níveis perceptivo e representacional. Apesar da sua importância, a compreensão dos processos neurológicos como respaldo para certas formas de conhecimento ainda é um programa desafiador. Para uma das formas perceptivas mais estudadas (a percepção visual), Edelman e Tononi (2000) propõem uma simulação computacional (redes neurais), mostrando o teor complexo das interações envolvendo um 
processamento multimodal (cor, forma, movimento). Nessa perspectiva, em consonância com a abordagem de Edelman e Tononi (2000), Gallese e Lakoff (2005) propõem a ideia de significado corpóreo associada àquilo que denominam 'exploração neuronal', a qual está intrinsecamente vinculada à correlação entre as ações que um organismo desempenha no ambiente e o mapa de correlatos neuronais que simulam tais ações. Essa é uma forma de pensar o significado corpóreo de forma menos fragmentada; é o que os autores parecem postular no seguinte trecho:

Como veremos, os circuitos nas regiões do cérebro vinculam modalidades, impregnando cada uma com as propriedades de outras. O sistema sensório-motor do cérebro é, portanto, 'multimodal' e não modular. Assim a linguagem é inerentemente multimodal nesse sentido, ou seja, usa modalidades ligadas entre si - visão, audição, toque, ações motoras e assim por diante. A linguagem explora o caráter multimodal pré-existente do sistema sensório-motor. Se isso for verdade, segue-se que não existe um 'módulo' único para a linguagem - e que a linguagem humana faz uso de mecanismos também presentes em primatas humanos. (GALLESE; LAKOFF, 2005, p. 2. Tradução livre.)

Os autores criticam diretamente a ciência cognitiva de primeira geração, que apostava numa versão descorporificada e modular da mente, especialmente nos termos da formulação de Fodor (1975). Recorrendo à noção de multimodalidade em termos de processamento neuronal, os autores ressaltam o dinamismo marcado por integrações e reentrâncias como características importantes do funcionamento cerebral. Nessa formulação, a multimodalidade não é um efeito de misturas sensoriais, mas antes uma funcionalidade do sistema cortical 'pré-existente no sistema sensóriomotor', de modo que o que está em jogo é o dinamismo das interações corticais, mais do que os mapeamentos, não obstante a importância desses últimos. Um outro conceito assume uma importância central na postulação de Gallese e Lakoff (2005), a saber, a de simulação, segundo a qual todas as ações humanas se acham, antes mesmo de sua realização no mundo da vida, estruturadas no cérebro. Nas palavras dos autores:

Quando se imagina ver algo, parte da mesma área do cérebro é usada igualmente quando se vê de fato. Quando imaginamos nos mover, parte da mesma área do cérebro é usada igualmente quando de fato nos movemos. (...) De fato, é exatamente isso 
que discutiremos. Ao fazer isso, estenderemos o que sabemos sobre fazer e imaginar, compartilhando um substrato comum por meio da seguinte hipótese: o mesmo substrato neural usado na imaginação é usado no entendimento (GALLESE; LAKOFF, 2005, p. 2. Tradução livre.)

Com efeito, os autores assumem a perspectiva da teoria neuronal da linguagem (NTL) (FELDMAN; NARAYANAN, 2004), segundo a qual os significados emergem de simulações neurais, em termos da ativação de grupos neuronais necessários para perceber, imaginar ou realizar uma ação, por exemplo. Nesse sentido, redes de neurônios espelho, pré-motores e parietais são especialmente importantes e essencialmente multimodais, de modo que essa multimodalidade atende à condição de que um conceito de ação deve contemplar tanto o desempenho quanto a percepção da ação. Os chamados grupos funcionais são redes corticais que funcionam como uma unidade relativa a computações neuronais relevantes, moldadas pela experiência, em termos da interação entre organismo e ambiente. Esses grupos constituem uma rede de integrações multimodais de alto nível, disseminada por regiões diferentes do cérebro e requerida por conceitos. Segundo os autores:

Argumentaremos que o conhecimento conceitual é incorporado, isto é, é mapeado dentro do nosso sistema sensório-motor. Argumentaremos que o sistema sensório-motor não apenas fornece estrutura ao conteúdo conceitual, mas também caracteriza o conteúdo semântico dos conceitos em termos da maneira como funcionamos com nossos corpos no mundo. (...) Nossa proposta não é uma teoria internalista do significado. A razão é que a imaginação, tal como o perceber e o fazer, é incorporada, isto é, estruturada por nosso constante encontro e interação com o mundo através de nossos corpos e cérebros. O resultado é uma teoria interacionista do significado. (GALLESE; LAKOFF, 2005, p. 2. Tradução livre.)

Além do substrato neurofisiológico da corporificação multimodal do significado, um outro aspecto importante sobre a questão da multimodalidade, que talvez minimize um pouco certas discrepâncias conceituais de uma apropriação relativamente livre que o termo assume, é uma distinção necessária entre multimodalidade perceptiva e multimodalidade representativa. Na perspectiva da primeira dimensão 
está o conceito mais restrito do termo, que se constitui num processo natural e orgânico de combinação, de complementação perceptiva - nada seria percebido apenas através de uma única modalidade perceptiva. A segunda dimensão, importante na expressão cultural, constitui-se por um trabalho de codificação e pode tornar-se necessária à expressão de certos gêneros discursivos.

Esse é certamente um fator importante da discussão sobre a multimodalidade, a ser considerado do ponto de vista teóricometodológico, mas o mais relevante é que as duas dimensões funcionam juntas no processamento do sentido e na experienciação dos fenômenos em nossos nichos bioculturais. Na dimensão perceptiva da multimodalidade, podemos destacar a abordagem de Gibson (1983) como paradigmática, em termos da forma de conceber o funcionamento do aparato sensório-motor:

Devemos conceber os sensores externos de uma nova forma, como ativos mais que passivos, como sistemas mais que canais e como interrelacionados mais do que mutuamente exclusivos. Se eles funcionam com o objetivo de captar informações e não apenas como instrumentos para manifestação de sensações, esta função deve ser denotada por um termo diferente. Eles serão aqui denominados sistemas perceptivos (GIBSON, 1983, p.47. Tradução livre.)

Aqui, ratificamos a posição de Gibson (1983), ramificada por grande parte das áreas que discute a cognição animal e, de modo mais específico, a humana. Diríamos que o paradigma se faz representar hoje pelas relações entre um organismo e o seu ambiente: são padrões enativos específicos que engendram o comportamento do organismo nesse ambiente. $\mathrm{O}$ ambiente, através de affordances disponíveis nos objetos, nas substâncias, age sobre o organismo e este, valendo-se do que lhe é ofertado pelos objetos e substâncias, age sobre o ambiente. Os sistemas perceptivos (o de orientação básica, o visual, o auditivo, o háptico e olfativo-gustativo) representam uma forma de ordenação do ambiente e contribuem, efetivamente, para a auto-organização do organismo: aqui começamos a lapidar o nosso processo de conhecimento; de dar a ele alguma forma de racionalização. Nessa etapa, compensa ao menos admitir que o organismo busca formas de organização de suas condutas sobre o ambiente e os sistemas perceptivos o conduzem a uma 
forma de identidade. Esses sistemas convergem para a construção de uma identidade de um organismo e de sua auto-organização.

A representação (ou sistemas de representação) constitui uma etapa posterior de organização (meta)linguística e semiótica e tem como base as etapas anteriores. Aqui os processos de conhecimento assumem um teor organizacional maior e podem ser expressos através de formas de representação diferentes (uma língua natural e/ou outros sistemas semióticos) para configurar níveis de linguagem diferentes, validando concepções que atendem à funcionalidade do organismo, como aquelas que atendem a funcionalidades de um corpo social maior e suas práticas de linguagem (a exemplo da blogosfera).

$\mathrm{Na}$ dimensão representativa da multimodalidade, podemos ressaltar a formulação de Forceville (2009), que desenvolveu um quadro teórico-metodológico relevante sobre as metáforas multimodais, a partir de uma perspectiva cognitiva. $\mathrm{O}$ autor reconhece a importância da relação entre as dimensões perceptiva e representativa, afirmando que "uma primeira aproximação leva-nos a dizer que um modo é um sistema de signos interpretáveis por causa de um processo perceptivo específico" (FORCEVILLE, 2009, p. 22). Assim, o autor elenca os seguintes modos: "(1) o modo pictórico ou visual; (2) o modo auditivo ou sonoro; (3) o modo olfativo; (4) o modo gustativo; (5) o modo tátill". Tal como abordado anteriormente, esses modos fariam parte da multimodalidade perceptiva. Todavia, conforme o próprio autor questiona, os modos propostos inicialmente seriam "muito crus", uma vez que corresponderiam a processos sensório-perceptuais, sem uma elaboração simbólica e/ou representacional mais desenvolvida; e, além disso, apresentariam uma dificuldade de serem distinguidos. Tal como exemplifica Forceville (2009), numa categorização como essa, haveria uma sobreposição entre som e língua falada, música e sons não-verbais. $\mathrm{O}$ autor adverte sobre a impossibilidade de elencar uma lista exaustiva dos modos, mas propõe, por fim, os seguintes: "(1) signos pictóricos; (2) signos escritos; (3) signos falados; (4) gestos; (5) sons; (6) música; (7) cheiros; (8) gostos; (9) toque" (FORCEVILLE, 2009, p. 23). Consideramos que a última categorização proposta trata os modos enquanto elaborações semióticas do processamento cognitivo, para além de uma categorização de ordem apenas sensório-perceptual. Com efeito, não obstante o caráter necessário dos processos perceptivos, o autor dedicou-se à análise de metáforas multimodais, enfatizando a sua dimensão representativa, a partir de textos ilustrativos de determinados gêneros. 


\section{Nichos bioculturais e cognição distribuída e blogosfera política}

Antes de adentrarmos numa discussão sobre as metáforas e blends multimodais, apresentaremos duas noções que são bastante relevantes para a nossa discussão. A primeira delas é a de nicho biocultural (SINHA, 2009), que se refere a repertórios ecológicos evolutivamente desenvolvidos, os quais são constitutivos do modo específico de ser/viver/ agir de certas espécies animais, entre elas, o homem. Segundo o autor:

Nós podemos chamar nosso complexo nicho biocultural de semiosfera humana, o ambiente significativo, construído, que é reproduzido através das gerações humanas do mesmo modo que acontece com o próprio organismo humano. É crucial apreciar, nesse contexto, que a semiosfera, como outros nichos artefatuais animais, não é meramente um constituinte do que é reproduzido, mas é também um mecanismo fundamental no processo de reprodução e transmissão. Por causa de sua pré-eminência na mediação entre a reprodução cultural e os processos cognitivos individuais, a linguagem é o primeiro e mais distintivo constituinte da semiosfera humana (SINHA, 2009, p. 305. Tradução livre.).

A complexidade de nosso nicho biocultural que se traduz pela semiosfera humana é constituída por uma rede de esferas de atividades sociais que se atualizam através de diversas práticas de linguagem, inscritas em diferentes gêneros e suportes, que formam um contínuo, desde a conversação espontânea até as plataformas de comunicação digital, construídos de forma multimodal. Nesse sentido, nossa concepção converge com o que Sinha (2009, p. 306) chama de teoria biocultural da linguagem, a qual, segundo ele, "instaura, literalmente, a vida na linguagem, por muito tempo reduzida a estruturas e operações formais". Assim, as espécies configuram seus nichos ao mesmo tempo em que são recursivamente configuradas por eles. Os sistemas perceptivos estão na base da nossa capacidade de produzir/interpretar signos, textos, discursos e toda gama variada de artefatos culturais que constituem nossa semiosfera. Mas estes últimos, ao mesmo tempo, influenciam e transformam a nossas percepções, que se adaptam ao seu nicho, com suas affordances (GIBSON, 1983) e possibilidades de interação. Isso favorece as propriedades emergentes da sociedade e dos organismos.

Nessa perspectiva, a segunda noção que nos interessa apresentar é a de cognição distribuída (HUTCHINS, 2000), que se articula 
organicamente à primeira, na medida em que preconiza a ideia de que os processos cognitivos baseiam-se nos sistemas perceptivos, mas são sociais, situados (pressupondo a capacidade de atenção conjunta) e distribuídos pelos artefatos culturais e/ou tecnológicos de uma sociedade. Nas palavras de Hutchins (2000):

Pelo menos três tipos interessantes de distribuição do processo cognitivo tornam-se aparentes: os processos cognitivos podem ser distribuídos entre os membros de um grupo social, os processos cognitivos podem ser distribuídos no sentido de que o funcionamento do sistema cognitivo envolve a coordenação entre o sistema interno e a estrutura externa (material ou ambiental), e os processos podem ser distribuídos através do tempo, de tal forma que os produtos de eventos anteriores possam transformar a natureza dos eventos posteriores. Os efeitos desses tipos de distribuição de processos são extremamente importantes para uma compreensão da cognição humana. (HUTCHINS, 2000, p. 20. Tradução livre.)

Tal formulação reconhece o princípio da mente corporificada, segundo o qual nosso pensamento e nossas ações são cognitivamente estruturados a partir de nossas capacidades sensório-perceptuais e das condições de inte(g)ração organismo/ambiente. Mas avança na direção da cognição social, enquanto fenômeno emergente em condições históricas e culturais específicas, resultante de ações discursivas de sujeitos socialmente relacionados e situados. E mais, assume o caráter dinâmico e distribuído da cognição, no sentido de estar inscrita e de circular por meio de uma gama complexa e variável de artefatos constitutivos de nossas tecnologias discursivas/semióticas. A questão central é que a construção dessas tecnologias não é concebida como algo acessório ou auxiliar na interação entre os sujeitos no seu nicho biocultural, mas como um elemento constitutivo dessa interação, de modo que os processos cognitivos são ao mesmo tempo mentais e sociais, implicando a instrumentalização tanto do ambiente quanto do próprio corpo.

Assim, os blogs políticos são exemplos ilustrativos de um tipo de ferramenta da nossa tecnologia discursiva, evidenciando aspectos significativos de nossos nichos bioculturais contemporâneos, de seus artefatos e de seu funcionamento em termos de cognição distribuída. A evolução da blogosfera está relacionada inicialmente à construção de diários pessoais na internet, os quais passaram a incorporar questões 
relativas ao espaço público, a partir do engajamento de jornalistas e de outros atores sociais em sua produção. Uma característica fundamental que tende a diferenciar a internet de outros meios de comunicação em massa é a interatividade e a dispersão da comunicação, de modo que a 'rede' permite uma circularidade e reversibilidade de papéis em termos de produção e interpretação das 'informações'. Nesse sentido, os blogs são construções online mais subjetivas, inicialmente voltados para a intimidade e a cotidianidade, e mesmo os blogs de opinião política caracterizam-se por estratégias de personalismo, apresentando um dualismo provocativo entre a opinião particular e os artigos e as matérias ou notas jornalísticas diárias. Os blogs de opinião são um dispositivo político-jornalístico que ilustra essa interatividade potencializada, configurando um espaço mais livre para estratégias de subjetivação, de caráter mais pessoal, mas que têm muitas vezes como titulares colunistas respeitáveis provenientes ou dissidentes das corporações de informação midiática. Os colunistas e seus leitores se representam como parte de uma elite cognitiva, cujas explicações e avaliações do mundo público têm influência na construção das expectativas e atitudes dos cidadãos acerca do governo e da política.

De um ponto de vista metodológico, em termos da escolha do objeto empírico a ser analisado, é preciso distinguir pelos menos quatro modalidades de $b \log _{s}$ sobre política: (i) os que são diretamente produzidos por partidos, profissionais da política ou por (grupos) ativistas; (ii) aqueles diretamente vinculados às corporações midiáticas tradicionais $\mathrm{e}$ hegemônicas; (iii) os vinculados a um portal informativo exclusivamente digital; e (iv) aqueles que são mantidos independentemente por jornalistas e outros experts conhecidos e reconhecidos, mas desvinculados de sua inserção institucional, assumindo, geralmente, a produção de um contradiscurso de resistência ao poder hegemônico instituído econômica, política e midiaticamente. São esses últimos que nos interessaram como objeto de análise e, entre eles, selecionamos um exemplar do Tijolaço, de Fernando Brito para ilustrar nossa abordagem.

\section{Da metáfora conceitual às metáforas multimodais}

Parece haver um consenso, entre os estudiosos da metáfora, de que a teoria da metáfora conceptual (TMC), formalizada em suas bases epistemológicas por Lakoff e Johnson (1980) representou, e ainda 
representa, uma quebra de paradigma no estudo da metáfora, concebida como processo de estruturação de um domínio conceitual/experiencial (alvo) em termos de outro (fonte). Como esse processamento metafórico, na perspectiva da TMC, pode ter como fundamento tanto a corporificação - em termos de experiências sensório-motoras de caráter mais universal, chamadas de esquemas imagéticos (JOHNSON, 2007) - quanto a dimensão cultural da experiência (KÖVECSES, 2005), estudar a metáfora passou a representar um importante instrumento para a compreensão do papel do corpo e da cultura, intermediados pela metáfora, na produção de sentidos.

A hipótese defendida é de que não só o corpo molda a mente corporificada, mas as experiências do corpo-no-mundo também moldam a mente corporificada. Assim, os mundos experienciais com os quais interagimos são mais do que simplesmente físicos, pois nascemos inseridos em meios sociais e culturais que transcendem nossos corpos individuais situados no tempo, sendo a linguagem constitutiva do meio sociocultural no qual existimos.

Não obstante a pertinência teórica da abordagem de Lakoff e Johnson (1980) e seus desdobramentos, em linhas gerais, esta última se caracteriza por analisar os processos metafóricos como operações cognitivas que nos permitem estruturar/projetar nosso conhecimento de determinados domínios experienciais em termos de outros, apresentando um escopo voltado para os princípios cognitivos mais gerais que regem o nosso sistema conceitual. Nesse sentido, tal abordagem não está diretamente interessada pela questão do processamento discursivo e de suas variáveis situacionais, pragmáticas etc., o que explica a ausência de um instrumental de análise mais consistente para dar conta de fenômenos emergentes mais localizados no plano da enunciação.

Forceville (2009), já mencionado acima, bem como Forceville e Urios-Aparisi (2009) estabelecem uma correlação entre multimodalidade e metáfora, partindo do princípio, estabelecido em obras seminais em Linguística Cognitiva, como Metaphors we live by (LAKOFF; JOHNSON, 1980), de que "a metáfora não é, primariamente, uma questão de língua, mas estrutura o pensamento e a ação" (FORCEVILLE; URIOS-APARISI, 2009, p. 3).Os autores elencam dois ou mais modos que se combinariam, de modo a constituírem metáforas multimodais, tais como: "(1) a língua escrita; (2) a língua falada; (3) imagens estáticas e em movimento; (4) música; (5) sons não-verbais; (6) gestos” (FORCEVILLE; 
URIOS-APARISI, 2009, p. 4), ressaltando que as mensagens verbais são complementadas ou mesmo sobrepostas por mensagens provenientes de outros sistemas significantes. Nesse sentido, pretendemos explorar, mais especificamente, a correlação entre linguagem verbal e imagens, dois modos semióticos de comunicação distintos, que se revelam complementares em muitas práticas discursivas pertencentes a diferentes gêneros e seus diversos suportes, a exemplo dos blogs. Assim, segundo Forceville:

Em contraste com metáforas monomodais, metáforas multimodais são metáforas cujos alvos e fontes são representados predominantemente em diferentes modos. A qualificação 'exclusivamente ou predominantemente' é necessária porque metáforas não verbais frequentemente têm alvos e/ou fontes que são sugeridas em mais do que um modo simultaneamente. (FORCEVILLE, 2009, p. 24. Tradução livre.)

A partir da categorização proposta, o autor ressalta a importância de analisar dados provenientes de contextos reais de interação na análise de metáforas sejam elas monomodais ou multimodais. Sendo as metáforas monomodais definidas como aquelas cujos domínios fonte e alvo ocorrem exclusivamente em um único modo, o seu representante prototípico seriam as metáforas verbais, embora, mais recentemente, as metáforas pictóricas/visuais e gestuais tenham sido também objeto de análise. Por outro lado, se as metáforas multimodais, como afirma o autor, são aquelas cujos domínios fonte e alvo ocorrem exclusiva ou predominantemente em dois ou mais modos, necessitamos levar em consideração a especificidade dos gêneros que instanciam tais metáforas e suas configurações semióticas. Chegamos a um ponto central de nossa formulação, pois toca diretamente na questão da enunciação e da interação com todos os aspectos fenomenais constitutivos de sua complexidade. Nossa hipótese é de que o dispositivo enunciativo, em seu funcionamento dialógico, está na base da semiosfera humana.

Esse interesse por uma abordagem da metáfora numa dimensão não apenas cognitiva/conceitual resultou em uma série de estudos, protagonizados, principalmente, por Cameron (2007), Cameron e Deignan (2006), Cameron e Maslen (2010), Cameron et al. (2009) e Semino (2008), que passaram a direcionar seus questionamentos para a dimensão discursiva da metáfora, propondo unidades de análise como 
o metaforema (metáfora nova, emergente, local, vinculada a um sistema complexo, candidata a convencionalização) e metáfora sistemática (metáfora cognitiva subjacente ao discurso, situada, ao contrário da metáfora conceptual, em textos específicos e evidenciada por marcas linguísticas metafóricas, ou veículos, presentes nesses textos). Nessa mesma direção, o conceito de nicho metafórico (VEREZA, 2010) vem contribuir para o entendimento da metaforicidade textualmente tecida, a partir de desdobramentos de uma ou mais metáforas locais ou episódicas, na medida em que conduz, cognitiva e discursivamente, todo um desdobramento ou mapeamento textual online, construindo um determinado objeto discursivo e um ponto de vista, uma perspectivação. Esses últimos estudos tendem a enfatizar o processo metafórico em sua emergência textual-discursiva, o que é, decerto, importante para nossa análise, mas requerem uma reflexão mais sistemática sobre princípios e operações que estão na base de seu processamento.

\section{Metáforas e blends multimodais: da teoria da integração conceitual à semiótica cognitiva}

Em nossa pesquisa recorremos, então, a outros modelos teóricos que desenvolveram enfoques mais adequados sobre os princípios e operações constitutivos do processamento metafórico numa dimensão cognitivo-discursiva, que estão na base da emergência de efeitos de sentido contextualmente situados. Segundo Silva:

Uma nova teoria em linguística cognitiva que subsume a metáfora e a metonímia como casos particulares de mecanismos de projeção mental é a teoria da mesclagem ou integração conceitual ("blending") - uma extensão dos estudos iniciais de G. Fauconnier sobre espaços mentais (Fauconnier: 1985) e que tem sido desenvolvida pelo próprio e por M. Turner e seus colaboradores [...] Esta nova teoria procura explicar como é que falantes e ouvintes registram correspondências conceituais e constroem novas inferências durante o processo discursivo. A ideia nova e central é a de que na projeção conceitual, tal como ocorre no discurso, os domínios origem e alvo (ou espaços input) são projetados num espaço integrado ("blend"), cuja estrutura não deriva inteiramente dos espaços input (SILVA, 2006, p. 147). 
Com efeito, para a teoria da integração conceitual (FAUCONNIER; TURNER, 2002), a metáfora é uma manifestação particularmente importante e saliente da integração conceitual ou mesclagem (blend), que emerge de uma rede articulada de espaços mentais, os quais podem ser definidos, em linhas gerais, como esquemas/cenários cognitivos construídos pelos sujeitos percebendo, imaginando e/ou interagindo. Resumidamente, ao passo que a teoria da metáfora conceitual identifica, prioritariamente, padrões regulares e convencionais de metáforas e trata, desse modo, de estruturas de conhecimento estáveis e representadas na memória de longo prazo, a teoria das redes de integração dirige-se explicitamente a exemplos novos e únicos, buscando modelar a evolução dinâmica das representações online de locutores em situações concretas.

$\mathrm{Na}$ arquitetura dos espaços proposta na teoria da integração conceitual (FAUCONNIER; TURNER, 2002), postula-se a existência de um espaço base/genérico, que mapeia estruturas partilhadas pelos espaços de entrada, a partir dos quais são projetados novos espaços integrados (mesclas) emergentes. O estatuto teórico do espaço base/genérico é pouco discutido pelos próprios autores da teoria e, por vezes, é criticado por outros estudiosos pela falta de clareza em sua definição. Em se tratando de uma análise do processamento discursivo de metáforas e blends multimodais, parece-nos importante desenvolver um breve comentário sobre essa questão, e o faremos a partir da discussão elaborada por Brandt e Brandt (2005).

Segundo esses autores, o espaço base/genérico da teoria da integração conceitual corresponde ao que era chamado de espaço-R, ou seja, aquele relativo à realidade do falante, que seria a base ontológica - o ponto de referência - para determinar o estatuto de outros espaços a ele relacionados, a exemplo de espaços contrafactuais ou hipotéticos. Nesse sentido, Brandt e Brandt (2005) propõem a formulação de um espaço base semiótico, como espaço de engajamento enunciativo dos sujeitos na produção de sentidos, o qual é desdobrado em três esferas: a da semiose propriamente dita, enquanto instância de realização de atos de linguagem, a da situação de comunicação em que se encontram os participantes da interação, e a do mundo fenomenológico mais amplo acessível à nossa experiência vivida.

O modelo da semiótica cognitiva de Brandt e Brandt (2005) dialoga diretamente com os fundamentos da teoria da integração conceitual, mas avança na análise do processamento discursivo, ao apresentar uma 
ancoragem enunciativa/discursiva mais clara e consistente, a partir do desdobramento do espaço base semiótico nos termos mencionados acima, ao qual se associa a postulação de um espaço de relevância (ilocucional, situacional e argumentativa), que articula a geração de sentidos emergentes no espaço virtual/integrado (blend) à sua pertinência em relação à prática discursiva em questão. Na versão apresentada pelos autores, a arquitetura dos espaços é composta pelo espaço base semiótico (a realidade enunciativa que envolve enunciador e enunciatário), pelos espaços de entrada, chamados de espaço de apresentação (instância da materialidade figurativa/textual) e de referência (instância objeto), e pelo espaço virtual (blend), projetado a partir da seleção de elementos dos dois últimos espaços. A esse conjunto se articula um espaço de relevância, que orienta o sentido emergente do espaço virtual em função de sua relação com os demais espaços. Segundo Brandt e Brandt:

O significado metafórico é um produto de uma projeção/ mapeamento entre o blend, em seu estado de significado-préemergente (o blend antes da emergência de inferências relevantes), e algum esquema relevante, que estrutura o blend e faz sua estranha figuratividade significativa. Da perspectiva de um destinatário, um blend pode atrair diferentes projeções esquemáticas dependendo de quais estruturas possam ser interpretadas como partilhadas entre as entradas e o que tenha sido estabelecido como situacionalmente relevante para a comunicação. Da perspectiva de um falante, a emissão relevante determinará a gama de possíveis cenários apresentacionais, e a adequação de qualquer candidato individual (BRANDT; BRANDT, 2005, p. 235. Tradução livre.).

Assim, o espaço de relevância parece operar uma filtragem no processo recursivo de projeções no(s) espaço(s) integrado(s), de modo a selecionar os frames pertinentes à interação em questão, em termos da produção de efeitos de sentido emergentes numa dada situação de comunicação. Apresentamos na Figura 1uma versão esquemática nossa da arquitetura dos espaços proposta por Brandt (2004) e adaptada por Oakley (2009), entre outros autores. 
FIGURA 1 - Arquitetura dos espaços

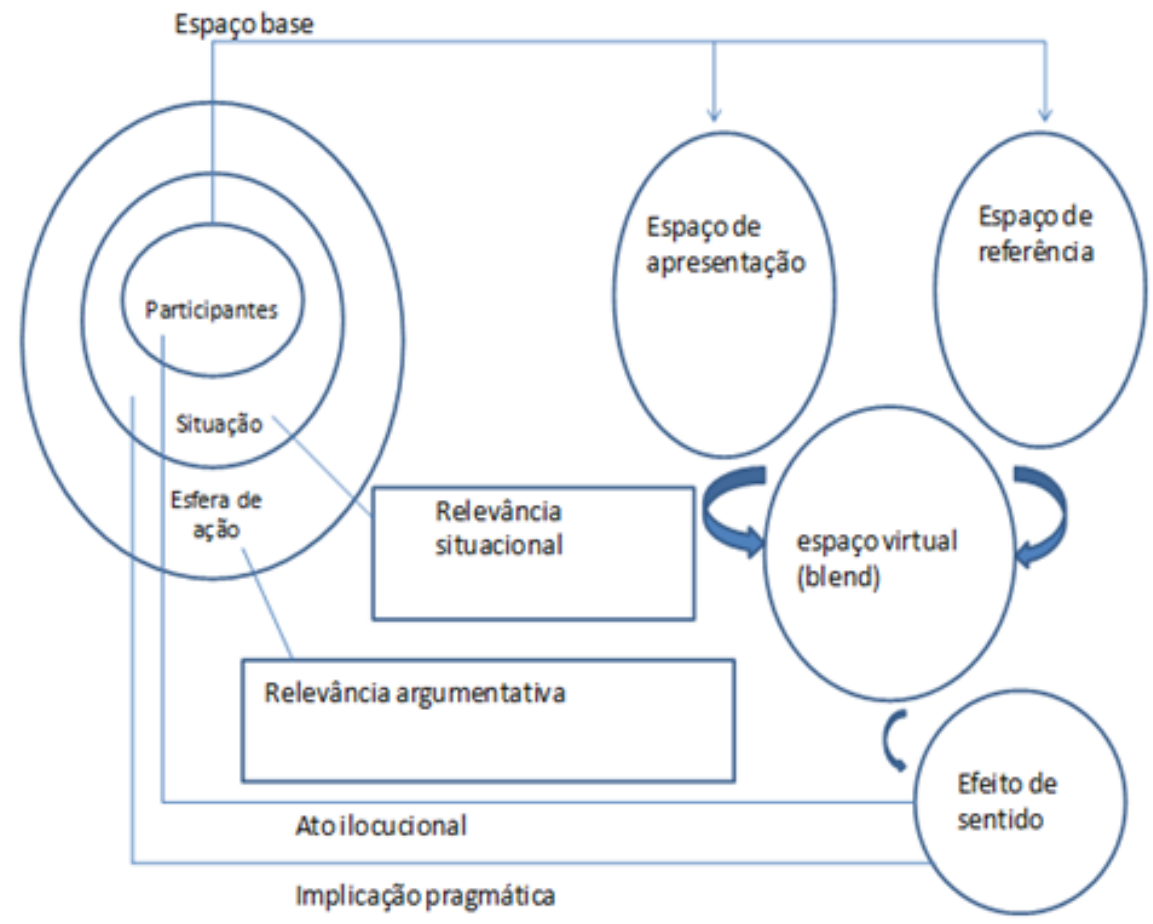

Fonte: Elaboração própria.

Com vistas a contemplar de modo mais claro e explícito a dimensão multimodal que é constitutiva da linguagem humana e pode ser instanciada textualmente, em termos de uma estrutura emergente que conjuga as expressões linguísticas com imagens, gestos etc., foi proposta a noção de blend multimodal (MIRANDA; MENDES, 2014), como forma de adaptação do modelo acima, de modo a evidenciar que o próprio espaço de apresentação pode configurar um processo de integração multimodal. O esquema adaptado encontra-se na Figura 2. 
FIGURA 2 - Arquitetura do blend multimodal

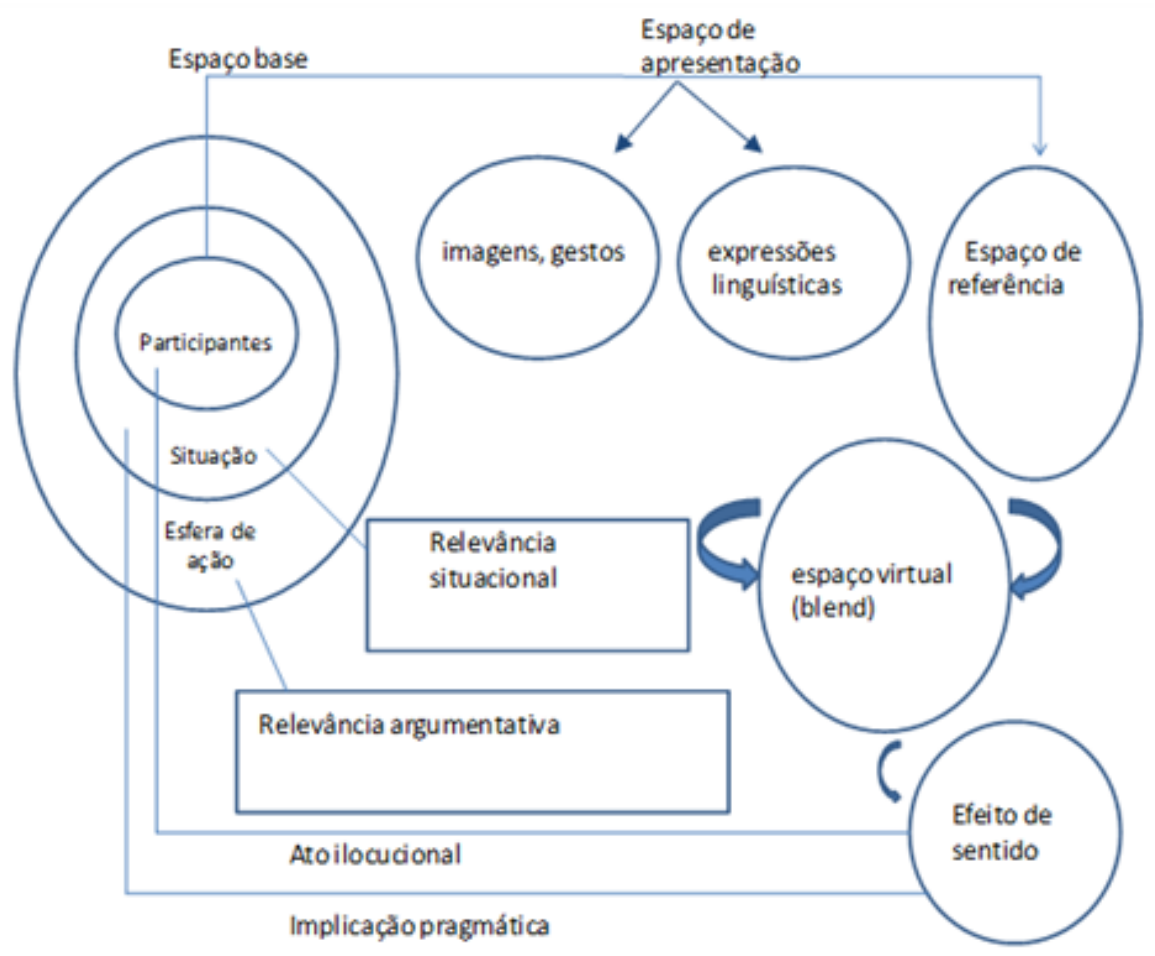

Fonte: Elaboração própria.

Em nossa concepção, os blogs políticos fazem parte de um espaço semiótico base, traduzindo-se por uma situação ou gênero discursivo, inserido, por sua vez, numa esfera de ação política mais ampla, que os engloba. Os frames/espaços de relevância dizem respeito, numa dimensão mais geral, a representações relativas às experiências políticas que caracterizam a história e a cultura de cada sociedade em questão (relevância argumentativa). Numa dimensão mais específica, esses frames/espaços remetem também a representações acerca da especificidade dos blogs (políticos) produzidos, funcionando como um dispositivo de parametrização da dinâmica de produção dos atos de linguagem, isto é, de construção do espaço de apresentação, através de recursos semióticos multimodais estratégicos, do espaço de referência, que configura os objetos políticos de que tratam, assim como do espaço 
virtual (blend), resultante da integração entre os dois espaços anteriores, o que engendra os efeitos de sentido, com suas implicações pragmáticas.

\section{Análise cognitivo-discursiva de metáforas e bends multimodais em um exemplo de blog político}

Nesta seção, vamos apresentar de maneira sintética um pequeno exemplo ilustrativo dos fenômenos aqui analisados, presentes no blog político Tijolaço, de Fernando Brito. Uma das características dos blogs políticos é apresentarem postagens fazendo referência a textos de outros autores, indicando tais textos, aludindo a eles ou mesmo "reproduzindoos", de modo a estabelecer uma rede intertextual recursiva. Nesse sentido, essas postagens apresentam na sua base um processo de integração de espaços (mentais) enunciativos, na medida em que se configuram a partir da organização de diferentes 'vozes' orquestradas/articuladas pelo blogueiro que assume, assim, a responsabilidade enunciativa pela postagem. No caso da produção de metáforas e blends multimodais, uma das formas mais recorrentes consiste na (re)produção de charges, fotos ou memes, que são acompanhados por textos verbais do próprio blogueiro, formando uma unidade semiótica integrada. Vejamos um exemplo básico desse processo:

"O tsunami da Educação afoga o governo"

POR FERNANDO BRITO·15/05/2019

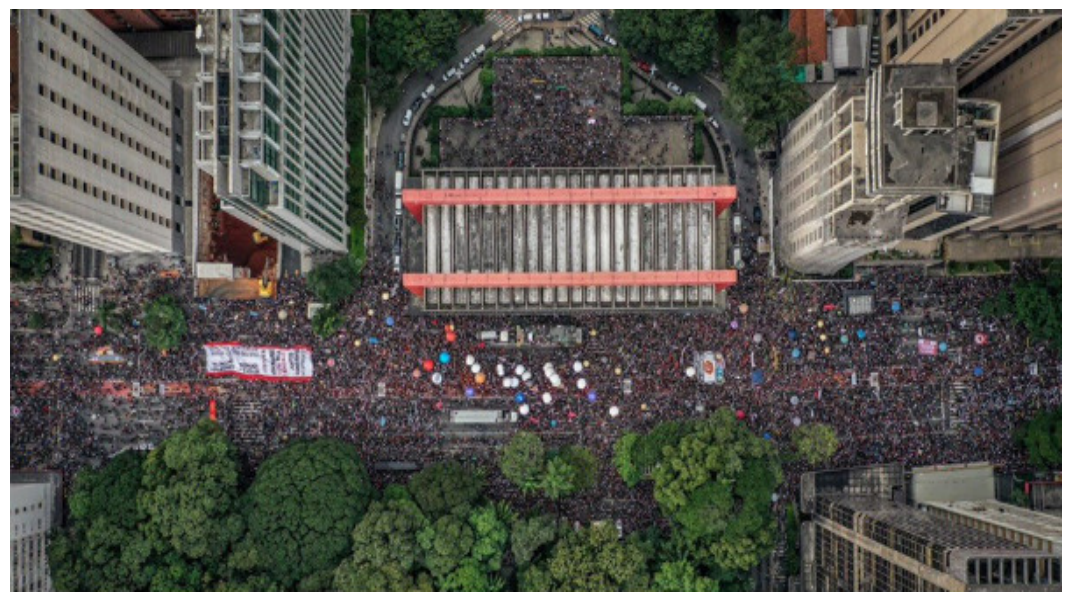


Escolhi esta foto da Avenida Paulista, lotada nas duas pistas diante do Masp e além dele, para suprir a impossível tarefa de publicar imagens das centenas de manifestações contra os cortes nas verbas da educação.

Logo ela será lembrada como um retrato do dia em que o Governo Bolsonaro começou a ser passado, embora ainda seja um pesadelo dos dias que vem por aí.

Porque é o dia em que o país voltou a acreditar em valores humanistas, depois do transe armamentista e policial que fizeram nosso povo viver.

É isso, é isso: é livro, é juventude - ela mesmo, com todas as suas irreverências e "balbúrdias" que um dia fizemos - pensando em viver melhor e em mais paz, não em revólveres e tacos de basebol, para matar e bater.

O dia em que percebemos que nossos sonhos, sonhos de gerações, começam a ser resgatados do sequestro que haviam feito, porque faz anos que o Brasil anda para trás.

Mas já não, já não...A gente percebe que a rua voltou a falar e, no seu ritmo, vai rugir.

A escolha desse exemplo para a análise tem uma intenção didática de ilustrar um processo mais elementar de construção de metáforas e blends multimodais. Aqui, é possível resgatar um conjunto de elementos relacionados a diversas abordagens sobre a metáfora e o blend. Primeiramente, podemos recuperar aspectos da formulação de Gallese e Lakoff (2005) sobre a primazia da mutimodalidade e do processo de simulação. Assim, ao lermos o título do post e olharmos a foto da Avenida Paulista repleta de manifestantes somos capazes de projetar integradamente a imagem de um tsunami formado por milhares de pessoas, que tem a força política de afogar o governo. Da mesma forma, ao lermos o texto escrito do post devemos ser capazes de processar outras metáforas nele presentes, simulando outras modalidades, como a háptica (de movimento e toque, inerentes à manifestação política) e a auditiva (também constitutiva da mobilização política), a exemplo da expressão “[...] faz anos que o Brasil anda pra trás. [...] A rua voltou a falar e, no seu ritmo, vai rugir".

Em seguida, podemos observar elementos da abordagem inicial de Lakoff e Johnson (1980) sobre a metáfora conceitual. Nesse sentido, a estruturação de um domínio alvo mais complexo (ou abstrato) em termos de um domínio fonte mais simples (ou concreto) pode ser 
ilustrado claramente em termos de metáforas conceituais altamente convencionalizadas ou entrincheiradas, a exemplo de CRISE POLÍTICA/ ECONÔMICA É DESASTRE NATURAL. Assim, o uso da expressão "tsunami" para se referir (conceptualizar) a crises político-econômicas é amplamente ostensivo e reconhecido socialmente, de modo a fazer parte do sistema conceitual de nossa sociedade. Poderíamos mencionar inúmeros exemplos dessa metáfora não só em blogs, mas em várias outras práticas de linguagem cotidiana, midiática ou institucional, nos quais tanto 'tsunami' quanto 'crise político-econômica' assumem valorações semânticoaxiológicas negativas, de um modo geral (MENDES; NASCIMENTO, 2013). No exemplo acima, especificamente, essa metáfora conceitual está na base do processo de metaforização, mas há uma variação interessante na sua construção, na medida em que o 'tsunami da educação' assume um valor positivo, que caracteriza, inclusive, a perspectivação ou o ponto de vista (posicionamento) do blogueiro.

Outro aspecto que podemos analisar diz respeito à formulação de Forceville (2009) sobre o fato de que o domínio fonte e o domínio alvo podem ser expressos através de modos semióticos distintos. Dessa forma, o título do post "Tsunami da educação afoga governo" é explicitamente metafórico, configurando um domínio fonte, caracterizado pela instanciação linguística de um processo de integração conceitual expresso tanto no sujeito da frase "Tsunami da educação" quanto no seu predicado "afoga governo". A ancoragem referencial que representa o domínio alvo da metáfora em questão é expressa pela foto (que é uma metonímia) das manifestações pela educação reproduzida pelo blogueiro e pelo seu comentário, a exemplo do enunciado que inicia o seu comentário: "Escolhi esta foto da Avenida Paulista, lotada nas duas pistas diante do Masp e além dele, para suprir a impossível tarefa de publicar imagens das centenas de manifestações contra os cortes nas verbas da educação."

Além disso, é possível também ilustrar aspectos das noções de metaforema, metáfora situada e, sobretudo, de nicho metafórico mapeando o conjunto de expressões metafóricas (destacadas em negrito) que constituem uma rede de referenciação e de perspectivação no post em questão - "governo Bolsonaro (...) ainda seja um pesadelo (...) transe armamentista e policial (...) nossos sonhos, sonhos de gerações, começam a ser resgatados do sequestro que haviam feito, porque faz anos que o Brasil anda para trás. (...) A gente percebe que a rua voltou a falar e, 
no seu ritmo, vai rugir". É claramente identificável o posicionamento crítico e o grau de subjetivação metafórica emergentes na enunciação do blogueiro, que se identifica abertamente com a mobilização da sociedade civil, incentivando-a a se manifestar contra os cortes realizados pelo governo nas verbas da educação.

Enfim, gostaríamos ainda de mostrar como a arquitetura de espaços mentais propostas por Brandt (2004) e adaptada por Oakley (2009) e por nós apresenta um poder explicativo e analítico do processo de metaforização e mesclagem multimodais presentes no post acima. Apresentamos, então, o esquema da Figura 3.

FIGURA 3 - Esquema de análise

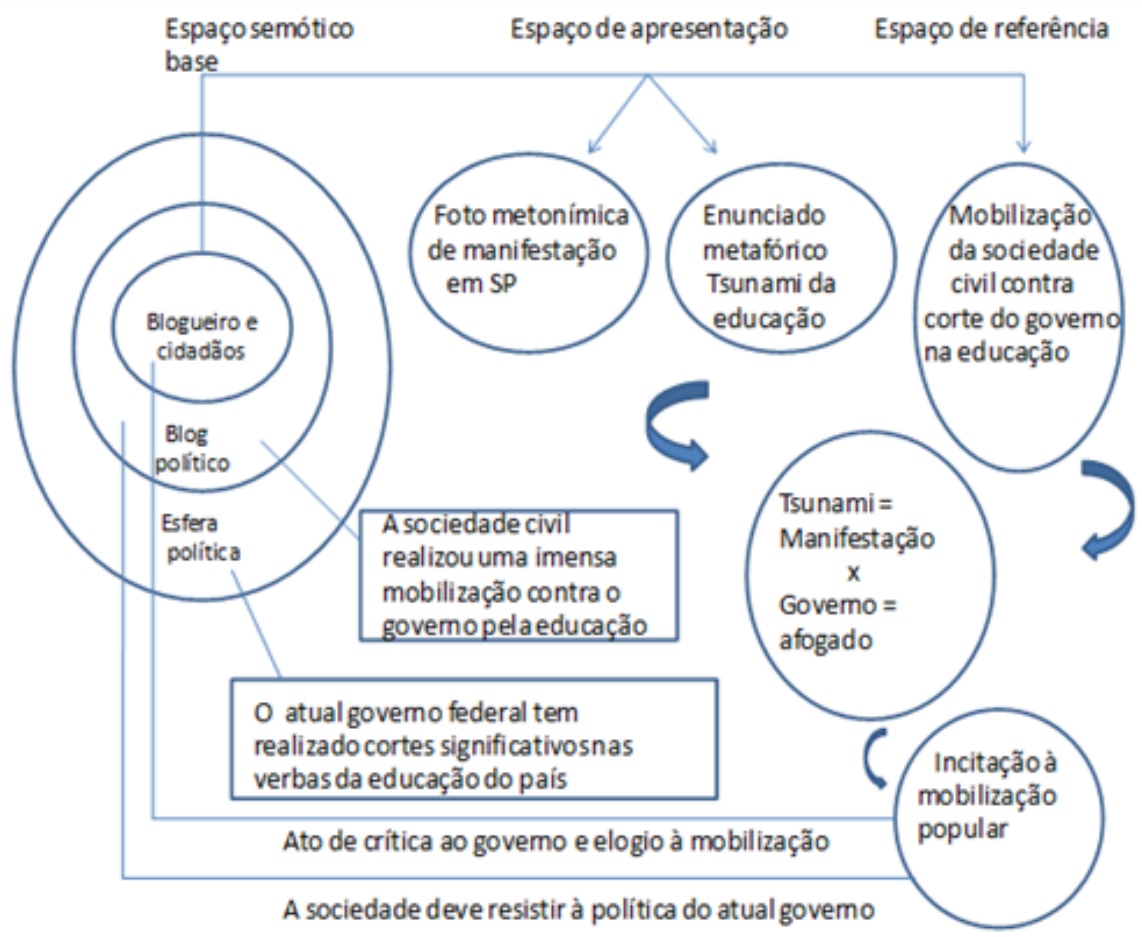

Fonte: elaboração própria.

O esquema da Figura 3 é uma síntese dos processos de metaforização e mesclagem multimodais presentes no post analisado, de modo que as condições de enunciação estão contempladas no espaço 
semiótico base a partir do qual todos os outros são produzidos. A partir da esfera de ação política, o blogueiro produz uma postagem dirigida aos seus 'leitores' enquanto cidadãos, através de um processo recursivo de integração entre recursos linguísticos metafóricos ("tsunami da educação afoga governo" etc.) e imagéticos metonímicos (foto da manifestação em SP contra cortes de verba da educação pelo governo), fazendo referência às mobilizações da sociedade civil ocorridas em todo país contra tais cortes. Essa relação intersubjetiva produz um blend metafórico multimodal em que a mobilização da sociedade civil é projetada numa relação de forças dinâmicas como um tsunami que afoga o governo e o pesadelo que ele representa para a população. O efeito de sentido produzido é de incitação à mobilização popular, através de atos de elogio à manifestação da população e de críticas à falta de política educacional do governo, gerando a implicação pragmática de que a sociedade deve resistir.

\section{Considerações finais}

Buscamos desenvolver neste texto uma reflexão sobre a relevância fundamental da multimodalidade para a cognição, a linguagem e a produção de sentidos, de um modo geral. Mais especificamente, destacamos algumas dimensões importantes sobre essa questão, a começar pelo seu substrato neurofisiológico, passando pela percepção até chegarmos a formas de representação e ação discursiva através de determinadas práticas de linguagem. Assim, nos dedicamos a uma análise de metáforas e de blends multimodais presentes em um blog político brasileiro, a saber, o Tijolaço, de Fernando Brito, o qual nos permitiu ilustrar a nossa abordagem teórico-metodológica, ancorada especialmente em modelos da linguística e da semiótica cognitivas, na sua interface com os estudos enunciativos e discursivos.

Nessa perspectiva, este artigo pretendeu trazer uma colaboração para o desenvolvimento de abordagens e metodologias que, a partir dedados empíricos, possam conferir maior credibilidade e confiabilidade às análises realizadas, antes baseadas apenas na introspecção e na intuição dos analistas. Não se trata de apostar em uma concepção de viés positivista, muito menos em qualquer tipo de reducionismo; pelo contrário, investimos na tentativa de explorar alguns princípios que estão na base ontológica e epistemológica da complexidade fenomenal dos 
nossos nichos bioculturais, a partir de uma integração entre fundamentos biocognitivos e sócio-discursivos. Assim, contemplamos a noção de cognição distribuída, como forma de avançar na proposta de um paradigma interacionista e experiencialista da produção, circulação e interpretação multimodal de sentidos, de modo a ressaltar a importância de gêneros emergentes na semiosfera humana, a exemplo da blogosfera. E mais, ressaltamos a importância de discutirmos aspectos relativos ao redimensionamento da esfera pública e da política a partir das novas ferramentas da tecnologia discursiva, que tem apresentado desafios concernentes ao exercício da cidadania e à própria existência das formas de democracia em nossa atual conjuntura.

\section{Referências}

BRANDT, P. A. Spaces, Domains, and Meaning: Essays in Cognitive Semiotics. Berna: Peter Lang, 2004.

BRANDT, L; BRANDT, P. A. Making Sense of a Blend. Annual Review of Cognitive Linguistics, Amsterdam, v. 3, p. 216-249, 2005. DOI: https:// doi.org/10.1075/arcl.3.12bra

BRANDT, P. A. The Mental Architecture of Meaning: A View from Cognitive Semiotics. Revista Digital de Tecnologias Cognitivas, São Paulo, n. 4, p. 25-36, jul.-dez. 2010.

BRITO, F. O tsunami da Educação afoga o governo. Blog Tijolaço, 15 maio 2019. Disponível em: Disponível em: http://www.tijolaco.net/blog/ o-tsunami-da-educacao-afoga-o-governo/. Acesso em: 15 maio 2019.

CAMERON, L. Confrontation or Complementarity? Metaphor in Language Use and Cognitive Metaphor Theory. Annual Review of Cognitive Linguistics, La Rioja, v. 5, p. 107-135, 2007. DOI: https://doi. org/10.1075/arcl.5.06cam

CAMERON, L.; DEIGNAN, A. The Emergence of Metaphor in Discourse. Applied Linguistics, Oxford, v. 27, n. 4, p. 671-690, 2006. DOI: https://doi.org/10.1093/applin/aml032

CAMERON, L.; MASLEN, R. (org.). Metaphor Analysis: Research Practice in Applied Linguistics, Social Sciences and the Humanities. London: Equinox, 2010. 
CAMERON, L. et al. The Discourse Dynamics Approach to Metaphor and Metaphor-Led Discourse Analysis. Metaphor and Symbol, [S.l.], v. 24, n. 2, p. 63-89, 2009. DOI: https://doi.org/10.1080/10926480902830821 EDELMAN, G.; TONONI, G. A Universe of Consciousness. New York: Basic Books, 2000.

FAUCONNIER, G.; TURNER, M. The Way We Think: Conceptual Blending and the Mind's Hidden Complexities. New York: Basic Books, 2002.

FELDMAN, J.; NARAYANAN, S. Embodied Meaning in a Neural Theory of Language. Brain and Language, [S.l.], n. 89, p. 385-392, 2004. DOI: https://doi.org/10.1016/S0093-934X(03)00355-9

FODOR, J. The Language of Thought. Cambridge: Harvard University Press, 1975.

FORCEVILLE, C. Non-Verbal and Multimodal Metaphor in a Cognitivist Framework: Agendas for Research. In: FORCEVILLE, C.; URIOSAPARISI, E. (org.). Multimodal Metaphor. Berlin; New York: Mouton de Gruyter, 2009. p. 19-42. DOI: https://doi.org/10.1515/9783110215366 FORCEVILLE, C.; URIOS-APARISI, E. Introduction. In: FORCEVILLE, C.; URIOS-APARISI, E. (org.). Multimodal Metaphor. Berlin; New York: Mouton de Gruyter, 2009. p. 3-18. DOI: https://oi. org/10.1515/9783110215366

GALLESE, V.; LAKOFF, G. The Brain's Concepts: The Role of the Sensor-Motor System in Conceptual Knowledge. Cognitive Neuropsychology, [S.l.], n. 25, p. 1-25, 2005.

GIBSON, J. The Senses Considered as Perceptual Systems. Connecticut: Greenwood Press, 1983.

HUTCHINS, E. Distribued Cognition. Toward a New Foundation for Human-Computer Interaction Research. ACM Transactions on Computer-Human Interaction, New York, v. 7, n. 2, p. 174-196, June 2000. DOI: https://doi.org/10.1145/353485.353487

JOHNSON, M. The Meaning of the Body: Aesthetics of Human Understanding. Chicago; London: The University of Chicago Press, 2007. DOI: https://doi.org/10.7208/chicago/9780226026992.001.0001 
KOVECSES, Z. Metaphor and Culture. Cambridge: Cambridge University Press, 2005. DOI: https://doi.org/10.1017/CBO9780511614408

LAKOFF, G.; JOHNSON, M. Metaphors We Live By. Chicago; London: The University of Chicago Press, 1980.

MENDES, P. H. A.; NASCIMENTO, M. do. O processamento metafórico em discursos sobre a crise econômica e a corrupção política no Brasil. In: SILVA, A. S.; MARTINS, J. C.; MAGALHÃES, L.; GONÇALVES, M. (org.). Comunicação política e económica: dimensões cognitivas e discursivas. Braga: Faculdade de Filosofia, Universidade Católica Portuguesa, 2013. p. 289-304.

MIRANDA, M. A.; MENDES, P. H. A. A emergência de metáforas multimodais: análise da metaforização e da compressão no debate político-eleitoral. Scripta, Belo Horizonte, v. 18, n. 34, p. 237-256, 2014. DOI: https://doi.org/10.5752/P.2358-3428.2014v18n34p237

OAKLEY, T. From Attention to Meaning: Explorations in Semiotics, Linguistics and Rhetoric. Berna: Peter Lang, 2009. DOI: https:/doi. org/10.3726/978-3-0351-0782-1

SEMINO, E. Metaphor in Discourse. Cambridge: Cambridge University Press, 2008.

SILVA, A. S. da. O mundo dos sentidos em português: polissemia, semântica e cognição. Coimbra: Almedina, 2006.

SINHA, C. Language as a Biocultural Niche and Social Institution. In: EVANS, V. (org.). New Directions in Cognitive Linguistics. Philadelphia: J.Benjamins, 2009. p.289-310. DOI: https://doi.org/10.1075/hcp.24.20sin

VEREZA, S.C. Articulating the Conceptual and the Discursive Dimensions of Figurative Language in Argumentative Texts. D.E.L.T.A, São Paulo, n. 26 Especial, p. 701-718, 2010. DOI: https://doi.org/10.1590/ S0102-44502010000300015 